\title{
TRANSFORMATIONAL LEADERSHIP
}

\section{AND ORGANIZATIONAL CULTURE}

\author{
BERNARD M. BASS \\ BRUCE J. AVOLIO \\ SUNY- Binghamton
}

\section{INTRODUCTION}

The organization's culture develops in large part from its leadership while the culture of an organization can also affect the development of its leadership. For example, transactional leaders work within their organizational cultures following existing rules, procedures, and norms; transformational leaders change their culture by first understanding it and then realigning the organization's culture with a new vision and a revision of its shared assumptions, values, and norms (Bass, 1985).

Effective organizations require both tactical and strategic thinking as well as culture building by its leaders. Strategic thinking helps to create and build the vision of an agency's future. The vision can emerge and move forward as the leader constructs a culture that is dedicated to supporting that vision. The culture is the setting within which the vision takes hold. In turn, the vision may also determine the characteristics of the organization's culture.

Transformational leaders have been characterized by four separate components or characteristics denoted as the 4 Is of transformational leadership (Avolio, Waldman, and Yammarino (1991). These four factors include idealized influence, inspirational motivation, intellectual stimulation, and individualized consideration. Transformational leaders integrate creative insight, persistence and energy, intuition and sensitivity to the needs of others to "forge the strategyculture alloy" for their organizations. In contrast, transactional leaders are characterized by contingent reward and management-byexception styles of leadership. Essentially, transactional leaders develop exchanges or agreements with their followers, pointing out what the followers will receive if they do something right as well as wrong. They work within the existing culture, framing their decisions 
and action based on the operative norms and procedures characterizing their respective organizations.

In a highly innovative and satisfying organizational culture we are likely to see transformational leaders who build on assumptions such as: people are trustworthy and purposeful; everyone has a unique contribution to make; and complex problems are handled at the lowest level possible. Leaders who build such cultures and articulate them to followers typically exhibit a sense of vision and purpose. They align others around the vision and empower others to take greater responsibility for achieving the vision. Such leaders facilitate and teach followers. They foster a culture of creative change and growth rather than one which maintains the status quo. They take personal responsibility for the development of their followers. Their followers operate under the assumption that all organizational members should be developed to their full potential.

There is a constant interplay between culture and leadership. Leaders create mechanisms for cultural development and the reinforcement of norms and behaviors expressed within the boundaries of the culture. Cultural norms arise and change because of what leaders focus their attention on, how they react to crises, the behaviors they role model, and whom they attract to their organizations. The characteristics and qualities of an organization's culture are taught by its leadership and eventually adopted by its followers.

At one extreme a leader accepts no deviation from standard operating procedures, managing-by exception in a highly transactional fashion while at the other extreme another leader rewards followers when they apply rules in creative ways or if they break them when the overall mission of the organization is best served. How leaders react to problems, resolve crises, reward and punish followers are all relevant to an organization's culture as well as how the leader is viewed both internally by followers and externally by clients/customers.

To reiterate, the culture affects leadership as much as leadership affects culture. For instance, a strong organizational culture, with values and internal guides for more autonomy at lower levels, can prevent top administration from increasing its personal power at the expense of middle-level administration. On a more specific level, the culture can affect how decisions are made with respect to such areas as recruitment, selection, and placement within the organization.

Leaders need to be attentive to the conservativeness reflected in beliefs, values, assumptions, rites, and ceremonies embedded in the 
culture that can hinder efforts to change the organization. They need to modify key aspects of culture, when it is possible to do so, to fit with new directions desired by the leadership and membership of the organization. For example, they can invent new rites to replace the old, some of which symbolize the value of change itself. An example is the ceremonial introduction of a new product or process to replace an older one. As organizations move across time, external constraints change forcing the company to question its deeply rooted assumptions and values.

As new members are brought into the organization, they too will often challenge deeply held assumptions even though organizations often hire people who have similar values to those dominant in the organizational culture. Consequently, it is incumbent upon the leaders in the organization to view the development of assumptions and values as an evolutionary process--a process by which the organization and its membership periodically question its assumptions and change them if the conditions warrant such change.

Early in its development, an organizational culture is the "glue" that holds the organization together as a source of identity and distinctive competence (Bass, 1991). Unfortunately, in an organization's decline, its culture can become a constraint on innovation since its roots are in the organization's past glories.

\section{ORGANIZATIONAL FOUNDERS AND CULTURE}

Organizational cultures are often the creation of their entrepreneurial founders. Founders often create an organizational culture from a preconceived "cultural scheme" in their head. Typically, the founder's and his or her successor's leadership helps shape a culture of shared values and assumptions guided and restricted by the founders' personal beliefs. The success or failure of an organization depends on the relevance of the founder's philosophical beliefs to the current opportunities and constraints confronting the organization.

Some founders originate agency cultures that they must leave to others to manage. However, in general, the facts are otherwise. Among the CEOs of the fastest growing companies in the United States in the $1980 \mathrm{~s}$, three-fourths were founders of their companies and 83 percent never made plans to retire. They remained on until they died leading their organizations.

To accomplish the needed changes in an organization's culture, it 
is essential for top administration to articulate the change that is required. The message may be of a vision that entails the type of leadership the organization should be known for in its intentions and behaviors with followers. An organization that wants to tap the expertise of its members to the fullest may highlight its "consultative" style of leadership. Changes, consistent with this message, are introduced in the daily practices of the organization. Desired role models of leadership begin at the top and are encouraged at each successive level below. The behaviors of top level leaders become symbols of the organization's new culture. Stories are created around the leader and mechanisms are developed to improve upward communication.

Leaders who are concerned about organizational renewal will seek to foster organizational cultures that are hospitable and conducive to creativity, problem solving, risk taking, and experimentation. First, there is an articulation of the changes that are desired. Next, the necessary changes in structure, processes, and practices are made and are widely communicated throughout the organization. Finally, new role and behavioral models are established and reinforced that become symbols of the "new" culture.

When trying to promote cultural changes in an organization, leaders should first understand and respect the past, returning to it for inspiration, instruction, and identification of past objectives, principles, and strategies that still must be maintained. Gardner (1990) pointed out that leaders need to understand and appreciate the "interweaving of continuity and change" for long-term purposes and values. Promotions should be made to ensure that these older values can survive despite the necessary changes. Values of trusting your people and respect will hopefully transcend time. Ceremonial events may be needed to mourn the loss of the "old ways of doing things." A symbolic act whereby the organization makes a clear break with its past can dramatically influence its culture.

Finally, changes should develop by providing reinforcement for innovative efforts that are attempted and successful, which fit with the new mission or vision for the organization. Trusting that the founder's vision of the organization's culture will transcend time is at best a questionable assumption and, at worst, the basis for organizational obsolescence. The truly great founders of organizations built into their cultures the need to question even their beliefs, assumptions, and values ... and to change them when needed. 


\section{TOWARDS A TRANSFORMATIONAL CULTURE}

While we can describe an ideal or "pure" transactional organizational culture and a "pure" transformational one, it is clear that organizations are likely to have cultures that are characterized by both styles of leadership. The authors' argument is that organizations should move in the direction of more transformational qualities in their cultures while also maintaining a base of effective transactional qualities.

A "pure" transactional culture focuses on everything in terms of explicit and implicit contractual relationships. All job assignments are explicitly spelled out along with conditions of employment, disciplinary codes, and benefit structures. Stories, rites, jargon, values, assumptions, reinforcement systems in the transactional organizational culture depend on setting a price on everything. Everyone has a price required for his/her motivation to work. There is a price on everything. Commitments are short-term. Self-interests are stressed.

Internally, the organization is a marketplace comprised of individuals in which each individual's reward is contingent on his or her performance. Management-by-exception is often actively practiced. Employees work as independently as possible from their colleagues. Cooperation depends on negotiations not problem solving or a common mission. Commitment is as deep as the organization's ability to reward members for successful performance.

There is little identification of the employees with the organization, its mission or vision. Superiors primarily are negotiators and resource allocators. Relatively few behaviors are determined by the norms of the organization, unless those norms reflect the transactional basis for doing business in the organization. Levels of innovation and risk taking may be severely curtailed in this type of organizational culture.

In a transformational culture, one fitting with the model of the four Is, there is generally a sense of purpose and a feeling of family. Commitments are long-term. Leaders and followers share mutual interests and a sense of shared fates and interdependence. A transformational culture like leadership can build on or augment the transactional culture of the organization. The inclusion of assumptions, norms, and values which are transformationally based does not preclude individuals pursuing their own goals and rewards. This can occur at the same time where there is alignment with a central purpose and the coordination required to achieve it. Leaders and 


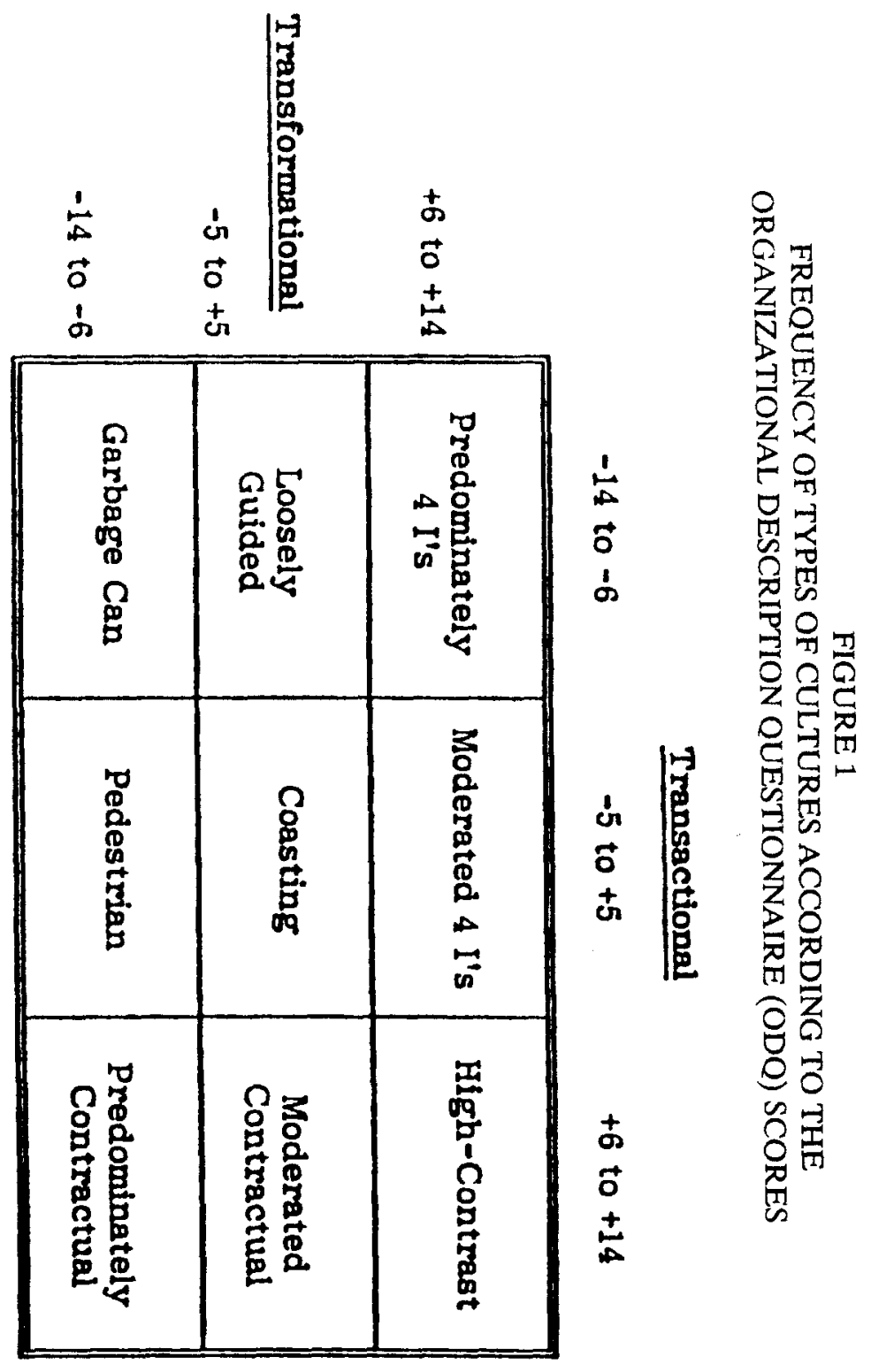


followers go beyond their self-interests or expected rewards for the good of the team and the good of the organization.

Superiors serve as mentors, coaches, role models, and leaders, socializing members into the culture, not necessarily because they are expected to do so but because they feel a personal obligation to help new members assimilate into the culture. There is a rich set of norms which cover a wide range of behaviors, norms that will adapt to and change with external changes in the organization's environment. There is much talk at all levels in the organization about purposes, visions, and meeting challenges.

\section{TYPOLOGY OF ORGANIZATIONAL CULTURES}

The Organizational Description Questionnaire (ODQ) is a 28 item survey questionnaire that can be completed by all or a sample of members of an organization. Fourteen items deal with transactional elements in the culture's assumptions, processes and expectations. For example:

-everyone bargains with everyone else for resources, -specific rules afford little opportunity for discretionary behavior, -you get what you deserve - no more, no less.

Fourteen items deal with transformational elements of culture. For example:

-people go out of their way for the good of the institution, -we believe in trusting each other to do the right thing, -individual initiation is encouraged.

Two parallel forms, A and B, have been constructed to facilitate resurveying after interventions. The ODQ generates two overall scores - the Transactional Culture Score (TA) and the Transformational Culture Score (TF). Organizations may be typed according to the mean scores obtained when their members are asked to describe their organizations using the ODQ as shown in Figure 1 (based on answers of members, their colleagues, and subordinates in one organization). Each of these types can be described as follows.

A predominantly and moderate transformational organizational culture tends to be characterized by a high ODQ transformational leadership score. The more negative the transactional ODQ score, 
the more the culture of the organization is regarded as one which is purely transformational. At this extreme, everyone is likely to be constantly talking about purposes, vision, values, fulfillment without emphasizing the need for formal agreements and controls. The lack of transactional specifications may make it difficult to be certain about what people will do. Trust is internalized rather than dependent on formal agreements and contracts. As the transactional score becomes less negative or even slightly positive, the culture will place more value on agreements, exchanges, and rewards for performance. The increase in transactional score leads to a greater balance in the organization's culture.

Expressiveness is likely to be high as in most high-functioning families. The organization's structure is likely to be loose, decentralized, and flat. The organization is flexible, adaptive, dynamic, informal, bottoms-up, with emphasis on the potential of its individual employees and the organization to grow and improve itself. Creativity is likely to be high in this environment with particular emphasis on questioning the methods used to accrue effective organizational performance. If transactional scores are extremely negative, newcomers and outsiders may have a problem knowing what to expect.

A high-contrast organizational culture tends to be characterized by high ODQ scores in transformational leadership coupled with a similar high level of transactional leadership. The high transactional score is likely to moderate some aspects of the transformational culture. You are likely to see a great deal of both management and leadership in this organization with conflict over the best ways to proceed. There is likely to be chafing and battling against the rules and the old ways of doing things, but much of the conflict is likely to be constructive. Maintaining a balance between the two will require trust in the individual and organization. This will be particularly true where tradeoffs must be made between short-term gain and individual rewards for the long-term benefit of the group and organization.

This organization is not highly structured. Whatever gets done occurs on the basis of informal leadership efforts. Predictability is low but there is some degree of flexibility shown.

A coasting organizational culture is neither extremely transformational nor extremely transactional and falls in the middle of the range. External controls, for example, are balanced with efforts towards self-control.

Management and leadership activity tends to be moderate in amount and the organization is likely to coast along but does not do 
as well as it might with the resources and opportunities it possesses. Little change is expected as the organization putters along. This pattern may represent an organization that is simply maintaining its current position.

Predominantly to moderate contractual organizational cultures are characterized as highly transactional in orientation and lacking in much transformational leadership. Self-interest is more important than the interest of the group. Each person watches out for his/her self-interests and short-term goals prevail. There is much attention to controls, directions, and standard operating procedures. The organization tends to be an internal market where much is negotiated according to the "rules of the game." The organization's structure is likely to be stable, centralized, tight, and tall with a clear top-down chain of command. Employees have little discretion and are watched, driven, and controlled. The organization tends to be rigid and mechanistic.

The pedestrian organization is moderately transactional with little or no transformational qualities. Little gets done that is not a consequence of formal agreements. Little change is observed. Risk taking is avoided. There is a general sense of structure and procedure which can take on different forms depending on the transactional items that were identified as true in the ODQ.

The organization is somewhat mechanistic. Leaders have and practice little discretion. Work is routine. There is little commitment to the organization or to other members. If the respondent answered true to items largely representing management-by-exception, the structure can highlight what is right versus wrong. If the respondent answered true to items which were more oriented toward contingent reward, then the structure would highlight the exchange of effort and good performance for rewards and recognition.

The garbage can organizational culture tends to be lacking in either transactional or transformational leadership. Consensus is likely to be absent. Everybody "does their own thing." The organization is a garbage can of fruitless activities. There is very little cooperation. Agendas depend on who shows up at meetings and the problems individuals carry around with them waiting for an arena in which to participate and to air their grievances. The organization is anarchic without either clear purposes, visions, and values or rules and regulations to control activities. 


\section{SUMMARY}

The purpose of the authors was to provide a framework for examining organizational cultures which parallels the factors they associate with a broad range of leadership behaviors, e.g., transformational through transactional and, to some extent, non-leadership. Their measure to describe organizational culture provides an assessment tool for determining an agency's culture in terms of the leadership and its effects found within the culture.

Currently, data are being collected using the ODQ with a broad array of community organizations to examine the connections between leadership, organizational culture, and performance. Based on prior research, the authors expect the more transformational cultures to provide the context for more effective organizational and individual performance.

\section{REFERENCES}

Avolio, Bruce J., David A. Waldman, and Francis J. Yammarino (1991). "The Four I's of Transformational Leadership." JOURNAL OF EUROPEAN INDUSTRIAL TRAINING 15(4):9-16.

Bass, Bernard M. (1991). STOGDILL AND BASS HANDBOOK OF LEADERSHIP. New York: Free Press.

(1985). LEADERSHIP AND PERFORMANCE BEYOND EXPECTA-

TION. New York: Free Press.

Gardner, John (1990). ON LEADERSHIP. New York: Free Press. 
Copyright of Public Administration Quarterly is the property of Southern Public Administration Education Foundation and its content may not be copied or emailed to multiple sites or posted to a listserv without the copyright holder's express written permission. However, users may print, download, or email articles for individual use. 